This item was submitted to Loughborough's Research Repository by the author.

Items in Figshare are protected by copyright, with all rights reserved, unless otherwise indicated.

\title{
Simulation study of particle-fluid two-phase coupling flow field and its influencing factors of crystallization process
}

\section{PLEASE CITE THE PUBLISHED VERSION}

https://doi.org/10.1007/s11696-018-0537-0

\section{PUBLISHER}

Springer International Publishing (c) Institute of Chemistry, Slovak Academy of Sciences

VERSION

AM (Accepted Manuscript)

\section{PUBLISHER STATEMENT}

This work is made available according to the conditions of the Creative Commons Attribution-NonCommercialNoDerivatives 4.0 International (CC BY-NC-ND 4.0) licence. Full details of this licence are available at: https://creativecommons.org/licenses/by-nc-nd/4.0/

\section{LICENCE}

CC BY-NC-ND 4.0

\section{REPOSITORY RECORD}

Wang, Wen-Rui, Zhao Li, Jia-Ming Zhang, and Han-Lin Li. 2019. "Simulation Study of Particle-fluid Twophase Coupling Flow Field and Its Influencing Factors of Crystallization Process". figshare. https://hdl.handle.net/2134/37739. 


\title{
Simulation Study of Particle-Fluid Two-Phase Coupling Flow Field and its Influencing Factors of Crystallization Process
}

\author{
Wen-rui Wang ${ }^{1}$, Zhao Li*1, Jia-ming Zhang1, Han-lin $\mathrm{Li}^{2}$ \\ ${ }^{1}$ School of Mechanical Engineering, University of Science and Technology Beijing, Beijing, \\ 100083, China \\ ${ }^{2}$ Loughborough Design School, Loughborough University, Loughborough, \\ LE11 3TU, UK \\ *Zhao Li, e-mail: renzhen_lizve@163.com
}

Received [Dates will be filled in by the Editorial office] 


\begin{abstract}
Obtaining the morphology of two-phase flow field accurately through experiments are very challenging, due to the complexity and the drainage area diversity of particle-fluid two-phase flow. Depending on the particle concentration, size, flow velocity and so on, the two-phase flow tends to be in a more complex form, known as Coupled Flow Status. Crystallisation process within a crystalliser is a typical engineering application of particle-fluid two-phase flow, and hence, the flow field within a potassium salt crystallizer is implemented to simulate the crystal suspension and to mix flow state during a continuous crystallisation process. Because of the two-fluid model treats the particle-phase and fluid-phase as two distinct continuous media, this simulation model takes the effect of virtual mass force into considerations. The enhanced two-fluid model is then applied to investigate the influencing factors of the coupled flow field between the potassium salt particles and the fluid in the crystalliser under various operating conditions. The results indicated that the stirring speed, the concentration of the feed particles and the particle size affected the distribution of coupled flow field at different levels, and thus, affect the crystallisation phenomena of a potassium salt. Among those factors, the stirring speed appears to have the most obvious effect on the flow field, as it affects the velocity of the two-phase flow. In the conditions listed in this paper, the minimum stirring speed is roughly $50 \mathrm{rpm}$ to form a stable and circular flow field in the crystallizer, and the maximum particle size is controlled at around $12 \mathrm{~mm}$ and the feed particle concentration of roughly $32 \%$ to ensure cyclic crystallization. The research method used in this article provides a baseline for the study of the coupled flow field of particle-fluid two-phase flow and its influencing factors. This research also states theoretical guidance for the optimisation of operating conditions in the production and application of potassium salt crystallizer.
\end{abstract}

Keywords: particle-fluid two-phase flow; coupled flow field; influencing factors; potassium salt crystallizer 


\section{Introduction}

Particle-fluid systems are not only the heart of the process industry, but it also closely related to the amplification effects that exist in the chemical industry (Zhu et.al 2007). Due to the complexity of particle-fluid two-phase flow and the diversity of drainage area, obtaining the morphology of two-phase flow field accurately through experiments are very challenging. Depending on the particle concentration, size, flow velocity and so on, the two-phase flow tends to be in a more complex form, crystallisation process in the crystallizer is one of the typical applications (Wadnerkar et al. 2012; Zhiqing 1994; Raeini et al. 2012). At present, a standard theoretical and computational model for the phenomenon of two-phase flow does not exist, and there is also a lack of studies regarding the influencing factor of the two-phase flow. Hence, many research for the two-phase flow in industrial applications is facing a long research period, high cost and device amplification difficulties (Hosseini et al. 2010). Therefore, the understanding of two-phase flow characteristic and its influencing factors, development of a standard theoretical and computational model for the flow field, analysis of the particle-fluid two-phase flow field, and the magnification calculation of the particle-fluid two-phase flow field are the most important research aspects in current theoretical and practical researches basis (Crowe et al. 2011).

The research on coupled flow field of particle-fluid two-phase flow has been studied for many years. The Single-Particle Dynamic (SPD) model considers only the forces acting on particles in a given flow field, and ignores the effects of particles on the flow field (Chen et al. 1999). Crowe proposed a Particle Trajectory (PT) model that considers the coupling effect between particles within a fluid domain, and suit extremely well for the systems with undefined particle sizes. However, this PT model requires a large amount of computer storage spaces as well as a high operating speed (Pratt et al. 1979). Bowen proposed a two-fluid model that considers particle-fluid as two distinct continuous media, and hence, takes the coupling effect between the fluid and the particles, in terms of mass, momentum and energy, into considerations. This model is widely accepted due to its stricter mathematical logic (Ding 
and Gidaspow 1990; Gidaspow 1993). Nowadays, there are still many knowledge gaps waiting to be filled in the research of two-phase flow model although this research area has made great progress. Furthermore, there is a lack of standard modelling and calculation method for the simulation of two-phase particle flow field (Wei and Youchu 2000)

In this paper, the developed simulation model considers the particle phase and fluid phase as two distinct continuous media. The particle phase is modelled using the pseudo-fluid model. Computational Fluid Dynamics (CFD) simulations are carried out for the following purpose: 1) determine the two-phase particle flow field in the crystallisation process of potassium salt; 2) analyse the two-phase flow field morphology under various working conditions; 3) assess the impact of stirring velocity, particle size and particle concentration on the two-phase flow field during the crystallisation process. The research method used in this article provides a baseline for the study of the coupled flow field of particle-fluid two-phase flow and its influencing factors. This research also states theoretical guidance for the optimisation of operating conditions in the production and application of potassium salt crystallizer.

\section{Particle-fluid two-phase flow principle of the crystallisation process}

In this paper, the flow field formed by the crystallisation process of potassium salt crystallizer was taken as the research, the crystallizer is designed for the crystallization production of raw materials with large particle size feed of $8 \sim 20 \mathrm{~mm}$, this crystallizer also improves the particle circulation. As shown in Fig. 1, the crystallizer consists of a recirculation zone, a crystallisation zone and a discharge zone and the total volume of the crystallizer is $1467.52 \mathrm{~m}^{3}$. The outer cylinder, the draft tube, the feed baffle and the bowl-shaped baffle are fixed on the crystallizer body. The two stirring devices are connected with the crystallizer body through the bracket and the bearing, and the main mixing device used is a three narrow blade mixer. There is also a mother liquor overflow port arranged at the upper end of the crystallizer body and a discharge port at the bottom. The bow-shaped baffle is located directly below the draft tube, and the diameter of the upper end of the bowl-shaped 
baffle is greater than the diameter of the lower end of the outer cylinder, the diameter of the bottom of the bowl-shaped baffle is equal to the diameter of the lower end of the draft tube. Finally, the centre of the crystallizer has a draft tube, whose shape is similar to the outer tube. Table 1 lists the main specifications of the crystallizer.

When the potassium salt crystallizer under operation, particles and fluid enter the recirculation zone from the inlet that located inside the material baffle and flows upward under the action of the main mixing device. Due to the gravity and the coupling effect between particles, the mixture flow velocity is reduced, and thus, the mixture flow downward along the annular gap after reaching the top of the draft tube. When the particles and fluid reach the bowl-type baffle, they inhaled to the draft tube again by the negative pressure generated from the high-speed rotation of the main stirring device and lead to a flow upward again, and hence, resulting in the formation of a closed loop circulation in the recirculation zone. In the meanwhile, supersaturated mother liquor flow to the crystallisation zone, the crystal flow to the bottom of the discharge zone after the crystallisation. When the slurry discharge is not sufficient, part of the solution is discharged from the decomposition overflow port. The particle suspension state has a great influence on the potassium salt crystallisation process. The information from the flow field of the particle-fluid is the external foundation of this particle suspension state, and therefore, the flow field distributions of particle-fluid two-phase directly affect the crystallisation process (Sha and Palosaari 2002; Jiang et al.2013)

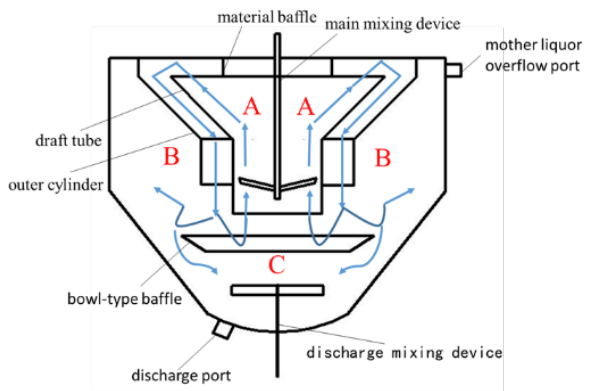

(A) recirculation zone; (B) crystallization zone; (C) discharge zone

(a) Crystallizer

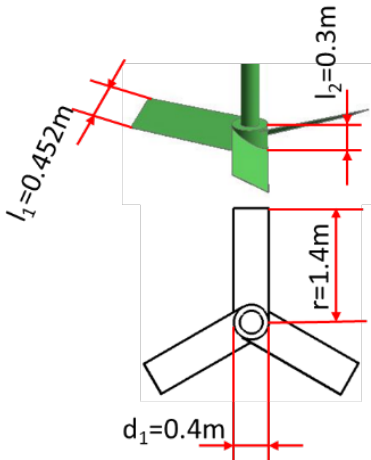

(b) Geometric dimension for the main mixing device and its Geometric dimension

Fig. 1. Schematic diagram of the crystallizer and main mixing device for investigation 
Table 1. The main specifications of the crystallizer

\begin{tabular}{cccc}
\hline & structure & Diameter $/ \mathrm{m}$ & height $/ \mathrm{m}$ \\
\hline crystallizer & Upper part & 15 & 5.839 \\
body & Lower part & - & 6.5 \\
\multirow{2}{*}{ draft tube } & Upper part & 9 & 3 \\
bowl-type & Lower part & 3 & 2.1 \\
baffle & Upper part & 7.8 & \\
\hline
\end{tabular}

\section{The equations of two-phase coupling flow field in the potassium salt crystallizer}

\section{Two-phase flow control equation considering bidirectional coupling}

For the two-phase flow systems, the two-fluid model considers the fluid and particle phases as a continuous media throughout the entire flow field, and the particle phase was defined as pseudo-fluid. Considering all possible interphase and phase interactions and applying the theory of fluid dynamics based on conservation of energy, the conservation of mass and momentum for two phases are determined by using the statistical averaging of the transient local transport equations. For simplicity, the following assumptions are made: isothermal flow, incompressible liquid phase and one size spherical particles. In CFD simulations the pressure setting of the particle phase is also applied to the fluid phase, and the viscosity of the particle is set infinitely small, as the particle phase and the fluid phase are interpenetrated in the same system.

Derived from the conservation of mass, the continuity equation for phase $j(j=1$ for fluid phase or s for particle phase) is as follows (Ljungqvist and Rasmuson 2001)

$$
\frac{\partial}{\partial t}\left(\varepsilon_{j} \rho_{j}\right)+\nabla \cdot\left(\varepsilon_{j} \rho_{j} \overrightarrow{u_{j}}\right)=0
$$

Where $\varepsilon_{j}, \overrightarrow{u_{j}}$, and $\rho_{j}$ represents respectively the volume fraction, velocity vector and the density of the $j$ phase. $\nabla$ is Laplace operator which is $\nabla=\sqrt{\frac{\partial^{2}}{\partial x^{2}}+\frac{\partial^{2}}{\partial y^{2}}+\frac{\partial^{2}}{\partial z^{2}}}$ 
The momentum conservation equation for the liquid phase is given by the Navier-Stokes equation, which is modified to include an interphase momentum transfer term:

$$
\frac{\partial}{\partial t}\left(\varepsilon_{l} \rho_{l} \overrightarrow{u_{l}}\right)+\nabla \cdot\left(\varepsilon_{l} \rho_{l} \overrightarrow{u_{l}} \overrightarrow{u_{l}}\right)=\varepsilon_{l} \cdot \nabla \cdot \overrightarrow{\tau_{l}}+\varepsilon_{l} \rho_{l} \vec{g}-\varepsilon_{l} \nabla p-\overrightarrow{F_{l s}}
$$

Where $\vec{g}$ is the gravity acceleration; $\mathrm{p}$ is the pressure; $\overrightarrow{F_{l s}}=\beta\left(\overrightarrow{u_{l}}-\overrightarrow{u_{s}}\right)$ is the phase momentum transfer phase; $\beta$ is the mutual transfer coefficient of momentum; $\overrightarrow{\tau_{l}}$ represents the viscous stress tensor of the liquid phase, which is $\overrightarrow{\tau_{l}}=\mu_{f}\left[\nabla \overrightarrow{u_{l}}+\left(\nabla \overrightarrow{u_{l}}\right)^{T}\right]-\frac{2}{3} \mu_{f}\left(\nabla \cdot \overrightarrow{u_{l}}\right) \vec{I}$. The eddy viscosity for the liquid phase is obtained by $\mu_{t}=c_{\mu} \rho_{l} k^{2} / \varepsilon$, and the effective viscosity of the fluid phase is $\mu_{f}=\mu_{l}+\mu_{t}$, a standard $k-\varepsilon$ turbulence model is not only simple, accurate, but also suitable for homogeneous fluids with high Reynolds numbers. It is widely applied in the simulation of industrial processes, and therefore, it is also considered in this paper. It calculates both the turbulent kinetic energy and dissipation rate of the liquid phase, $k$ is the turbulent kinetic energy and $\varepsilon$ is the dissipation rate of turbulent kinetic energy. Meanwhile, the influence of the dispersed particles on the liquid phase is neglected, the transport equations associated with these parameters are as follows:

$$
\begin{aligned}
& \frac{\partial}{\partial t}\left(\rho_{l} \varepsilon_{l} k\right)+\nabla \cdot\left(\rho_{l} \varepsilon_{l} \overrightarrow{u_{l}} k\right)=\nabla\left(\varepsilon_{l} \frac{\mu_{t}}{\sigma_{k}} \cdot \nabla k\right)+\varepsilon_{l} \mu_{t}\left[\nabla \overrightarrow{u_{l}}+\nabla\left(\overrightarrow{u_{l}}\right)^{T}\right]: \nabla \overrightarrow{u_{l}}-\rho_{l} \varepsilon_{l} \varepsilon \\
& \frac{\partial}{\partial t}\left(\rho_{l} \varepsilon_{l} \varepsilon\right)+\nabla \cdot\left(\rho_{l} \varepsilon_{l} \overrightarrow{u_{l}} \varepsilon\right)=\nabla\left(\varepsilon_{l} \frac{\mu_{t}}{\sigma_{\varepsilon}} \cdot \nabla \varepsilon\right)+c_{1} \varepsilon_{l} \mu_{t}\left\{\left[\nabla \overrightarrow{u_{l}}+\nabla\left(\overrightarrow{u_{l}}\right)^{T}\right]: \nabla \overrightarrow{u_{l}}\right\}: \frac{\varepsilon}{k}-\rho_{l} \varepsilon_{l} c_{2} \frac{\varepsilon^{2}}{k}
\end{aligned}
$$

The constants involved in the above equations are $C_{1}=1.44, C_{2}=1.92, C_{\mu}=0.09$, $\sigma_{k}=1.0, \sigma_{\varepsilon}=1.0$, respectively. These values have been proved to resolve the flow field in crystallizers by Reddy and Joshi and have been used in the current work (Sha et al. 2013).

The particle phase momentum balance is given by:

$$
\frac{\partial}{\partial t}\left(\varepsilon_{s} \rho_{s} \overrightarrow{u_{s}}\right)+\nabla \cdot\left(\varepsilon_{s} \rho_{s} \overrightarrow{u_{s}} \overrightarrow{u_{s}}\right)=-\varepsilon_{s} \nabla p-\nabla p_{s}+\varepsilon_{s} \nabla \overrightarrow{\tau_{s}}+\varepsilon_{s} \rho_{s} \vec{g}+f_{m}-\overrightarrow{F_{s l}}
$$


Where $p_{s}$ is the particle pressure which represents the normal particle forces due to particle-particle interactions, the particle stress tensor $\overrightarrow{\tau_{s}}$ can be expressed in terms of the bulk particles viscosity $\xi_{s}$ and solids viscosity $\mu_{s:}$

$$
\begin{aligned}
& p_{s}=\varepsilon_{s} \rho_{s} \theta+2 \rho_{s}(1+e) \varepsilon_{s}^{2} g_{0} \theta \quad g_{0}=\left[1-\left(\frac{\varepsilon_{s}}{\varepsilon_{s \max }}\right)^{1 / 3}\right]^{-1} \\
& \overrightarrow{\tau_{s}}=\mu_{s}\left\{\left[\nabla \overrightarrow{u_{s}}+\left(\nabla \overrightarrow{u_{s}}\right)^{T}\right]-\frac{2}{3}\left(\nabla \overrightarrow{u_{s}}\right) \vec{I}\right\}+\xi_{s} \nabla \cdot \overrightarrow{u_{s}} \vec{I}
\end{aligned}
$$

Where,

$$
\xi_{s}=\frac{4}{3} \varepsilon_{s}^{2} \rho_{s} g_{0}(1+e)\left(\frac{\theta}{\pi}\right)^{1 / 2}
$$

Radial distribution function $g_{0}=\left[1-\left(\frac{\varepsilon_{s}}{\varepsilon_{s, \max }}\right)^{1 / 3}\right]^{-1}, \overrightarrow{F_{l s}}=-\overrightarrow{F_{s l}}$

The momentum transfer between the coupled liquid phase and the particle phase is developed using drag model which is a crucial factor affecting flow behaviours of both particles and fluid phases. According to literature, for particle concentration greater than 0.2 , Ergun correlation is applied, and for concentration less than or equal to 0.2 , Wen and $\mathrm{Yu}$ expressions are applied (Chen and Wang 2014; Ergun 1952; Wen 1966). However, the transition makes the drag law discontinuous in particles concentration although it is continuous in Reynolds number. Physically, the drag force is a continuous function of both particles concentration and Reynolds number. Therefore Huilin (2004) proposed the continuous forms of the drag law to correct this phenomenon (Huilin et al. 2004). Huilin-Gidaspow model is stitched using a smooth function expressed in Eq. (8). Therefore the interface momentum transfer coefficient $\beta$ can be calculated by Eq. (9).

$$
\begin{gathered}
\varphi=\frac{\arctan \left[150 \times 1.75\left(0.2-\varepsilon_{s}\right)\right]}{\pi}+0.5 \\
\beta=(1-\varphi) \beta_{E}+\varphi \beta_{W Y} \text {, where, } \beta_{E}=150 \frac{\left(1-\varepsilon_{l}\right)^{2} \mu_{l}}{\left(\varepsilon_{l} d_{s}\right)^{2}}+1.75 \frac{\rho\left(1-\varepsilon_{l}\right)\left|\overrightarrow{u_{l}}-\overrightarrow{u_{s}}\right|}{\varepsilon_{l} d_{s}} \quad \varepsilon_{l} \leq 0.8 \\
\beta_{W Y}=\frac{3}{4} C_{d} \frac{\rho_{l}\left(1-\varepsilon_{l}\right)\left|\overrightarrow{u_{l}}-\overrightarrow{u_{s}}\right|}{d_{s}} \varepsilon_{l}^{-2.65} \quad \varepsilon_{l}>0.8
\end{gathered}
$$


The virtual mass force is another interfacial factor to be considered. This force is generated due to the expense of work done by the particles as they are accelerated through the fluid phase and leads the corresponding fluid to be accelerated as well. The virtual mass force is not negligible for accelerating flows. Gus'kov (2012) addressed the problem of the virtual mass of a sphere, moving in an ideal incompressible fluid (Gus 2012). Kendoush et al. (2007) performed experiments to evaluate the effect of virtual mass on solid sphere accelerating in fluids (Kendoush 2007). In stirred vessels, the particle acceleration depends upon the solid-solid interaction force, particle-fluid interaction force and the virtual mass force. By taking the virtual mass force into calculations, the results are significantly improved, and hence, this force is not negligible while considering accelerating flows.

The virtual mass force acting on a particle is given by Drew and Lahey (1993) (Roco 1993):

$$
f_{m}=-0.5 \varepsilon_{p} \rho_{l}\left(\frac{d u_{l}}{d t}-\frac{d u_{p}}{d t}\right)
$$

\section{Differential equations of fluid-particle motion (N-S equation)}

The fluid in the crystallizer is incompressible, and hence, the viscosity of the fluid is set to a constant. Considering the force between the liquid-solid phase and the solid-solid phase, and then performing the force analysis of the micro-hexahedron as shown in Fig. 2 (a). As a result, the vector-type differential equation of fluid motion is now obtained from momentum conservation equation (Elger and Roberson 2013).

$$
\left.\frac{\partial \overrightarrow{u_{l}}}{\partial t}+\left(\overrightarrow{u_{l}} \cdot \nabla\right) \cdot \overrightarrow{u_{l}}=\frac{\nabla \cdot \overrightarrow{\tau_{l}}}{\rho_{l}}+\vec{f}-\frac{\nabla p}{\rho_{l}}-\frac{\beta\left(\overrightarrow{u_{l}}-\overrightarrow{u_{s}}\right.}{\varepsilon_{l} \rho_{l}}\right)
$$




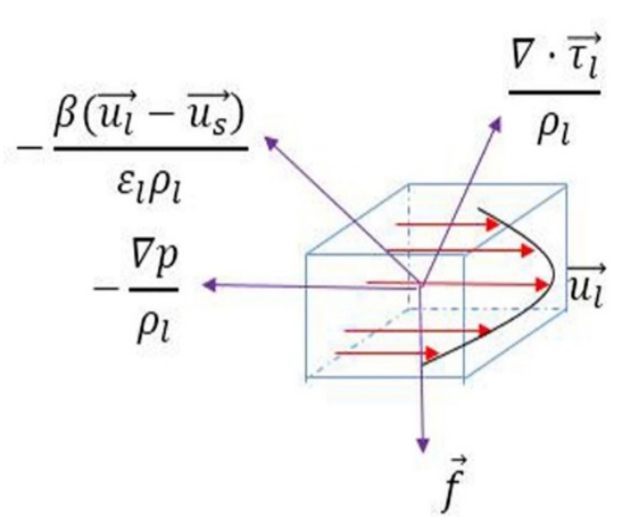

a) Force analysis of the micro-hexahedron

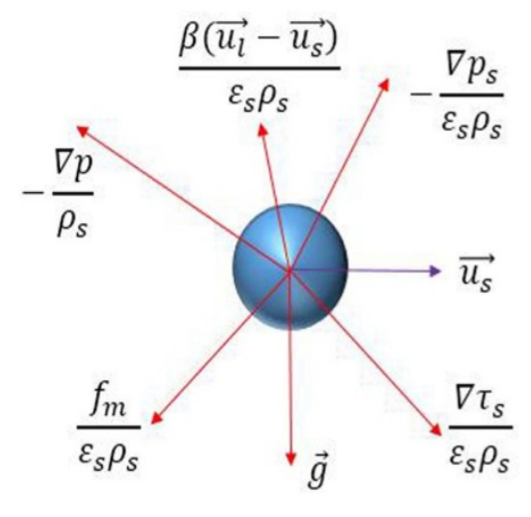

b) Force analysis of a particle

Fig. 2. Force analysis

While considering all the forces acting on the particle, the force analysis of a particle is performed using Fig. 2 (b), and the motion equation of the particle can be described as:

$$
\frac{\partial \overrightarrow{u_{s}}}{\partial t}+\left(\overrightarrow{u_{s}} \cdot \nabla\right) \cdot \overrightarrow{u_{s}}=-\frac{\nabla p}{\rho_{s}}-\frac{\nabla p_{s}}{\varepsilon_{s} \rho_{s}}+\frac{\nabla \tau_{s}}{\varepsilon_{s} \rho_{s}}+\vec{g}+\frac{f_{m}}{\varepsilon_{s} \rho_{s}}+\frac{\beta\left(\overrightarrow{u_{l}}-\overrightarrow{u_{s}}\right)}{\varepsilon_{s} \rho_{s}}
$$

By combining the boundary and initial conditions with the continuity equation, the velocity and pressure of each phase can be obtained by using Eq. (11) and Eq. (12).

\section{Flow field simulation of particle-fluid two-phase fluid coupling in the crystallizer Modelling}

A flow field model is developed to study the coupled flow field of particle-fluid two-phase flow in the crystallizer, with the actual working condition in mind. The first step of the simulation was to model the geometry and generate the body-fitted grids in the software ICEM 15.0 (Fluent Inc, USA). In order to reduce the number of calculations and simplify the model, the area below the discharge mixing device is not considered, and instead, the bottom is set as the outlet. The application of unstructured meshes is narrow, which only apply to geometry with a regular shape, the crystallizer model researched in this paper is rather complicated because there is the outer cylinder, the draft tube, etc. in the crystallizer, so unstructured meshes are applied in this paper. The crystallizer is divided into several regions, the element size is $0.2 \mathrm{~m}$ of the move zone, while the size of the move zone is $0.3 \mathrm{~m}$, the size of the interfaces is $0.1 \mathrm{~m}$, and the mesh near the main stirring device is encrypted. The number of 
grids is 2,136,029, and the model meshing result is shown in Fig. 3. Fig. 3 (a) shows the three-dimensional mesh of the meshing results and Fig. 3 (b) shows the central cross-section of the mesh results.

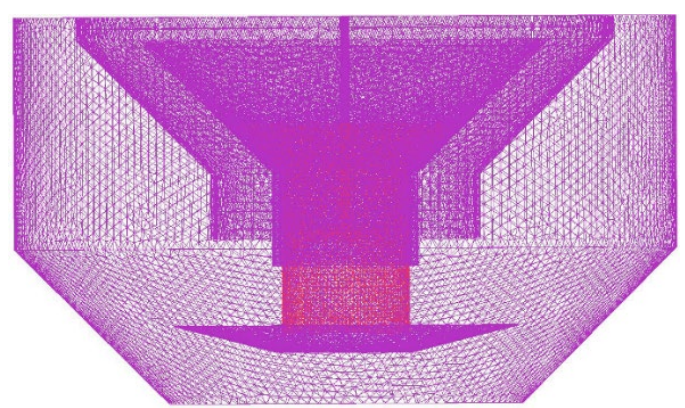

a) The three-dimensional mesh of the meshing results

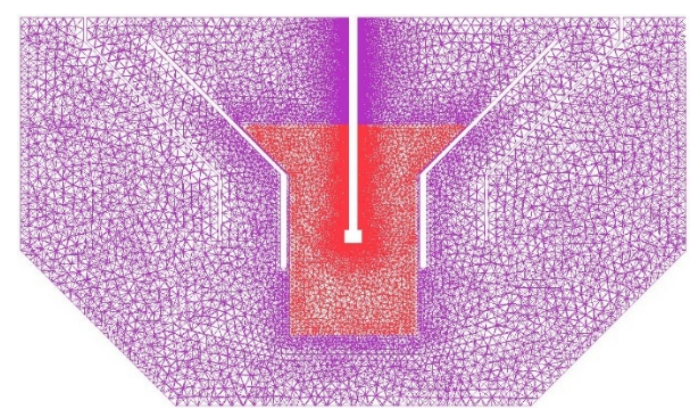

b) The ventral cross-section of the mesh results

Fig. 3. The meshing of the developed model at various locations

The research program is designated as follows: the continuous crystallisation process is simplified to a single particle size crystal suspension and simulation of particle-fluid flow state, the fluid density is set to $1250 \mathrm{~kg} / \mathrm{m}^{3}$, the viscosity of $0.005 \mathrm{~Pa} \cdot \mathrm{s}$; particle density of $1800 \mathrm{~kg} / \mathrm{m}^{3}$, the viscosity is set infinitely small. The simulation conditions are feed particle content of $32 \%$, the particle size of $15 \mathrm{~mm}$, stirring speed of $60 \mathrm{rpm}$.

\section{Initial and boundary conditions}

The CFD simulations were performed in the CFD software Fluent 15.0 (Fluent Inc, USA). The governing equations listed above were numerically solved with appropriate boundary and initial conditions. Initially, there were particles and liquid in the vessel, and it assumes that the liquid was still, and the floating particles were suspended uniformly in the liquid at the initial moment. As for the boundary conditions, the absolute velocities on the solid walls were all set to be zero, and a standard wall function was applied to treat the fluid flow in near-wall regions. The inner rotation region was solved under moving reference frame with rotational speed, and the mean mixing device is as the boundary of moving reference frame with the rotational speed, while the stationary zone was solved under stationary reference frame. The top inlet of the crystallizer was set as velocity-inlet boundary condition 
with the value to be $0.167 \mathrm{~m} / \mathrm{s}$, the fluid flows out uniformly from the bottom in the crystallizer, which can be seen approximately still, so the bottom face of the crystallizer was set as pressure-outlet boundary condition with gauge pressure to be 99,671 $\mathrm{Pa}$, obtained by the formula $p=\rho g h$, where $\rho$ is $1250 \mathrm{~kg} \mathrm{~m}^{-3}, \mathrm{~g}$ is $9.8 \mathrm{~m} / \mathrm{s}^{2}, \mathrm{~h}$ is the height of the model, which is $8.1364 \mathrm{~m}$. Based on the pressure-based implicit solver, the phase-coupled SIMPLE algorithm was used to solve the velocity-pressure coupling. All the terms of the governing equations were discredited with the second-order upwind scheme method. The convergence residual of each flow variable was set to $10^{-4}$.

\section{Flow field simulation results}

\section{Fluid velocity field distribution}

The velocity vector of the fluid represents the velocity distribution of the fluid, as shown in Fig. 4. In order to facilitate the analysis of the results, the central cross-section velocity vector diagram is provided, as shown in Fig. 4 (b). Due to the centrifugal force of the main agitator, the velocity changes are most significant in the vicinity of the main agitator, with a strong degree of turbulence. The fluid flows upward along the vertical vanes and flows into the annular circulation zone. The interaction force of particle-fluid and fluid-fluid are offset by gravity and causing a downward acceleration. The fluid flow velocity is much greater in the circulation zone than in other zones. This phenomenon is significant in the material circulation zone, and thus, indicating that there is sufficient circulation strength in the crystallizer under this condition.

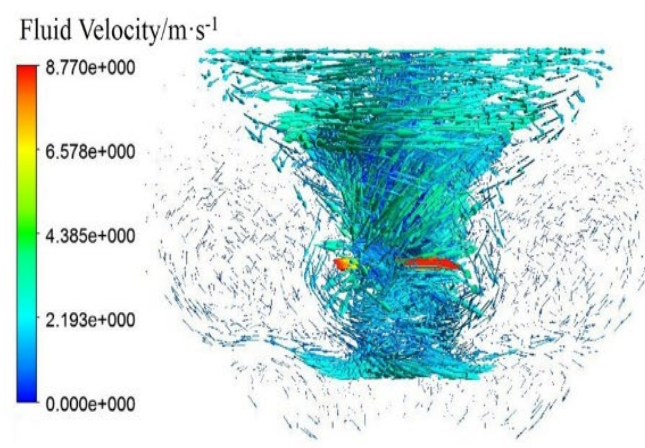

a) Three-dimensional velocity

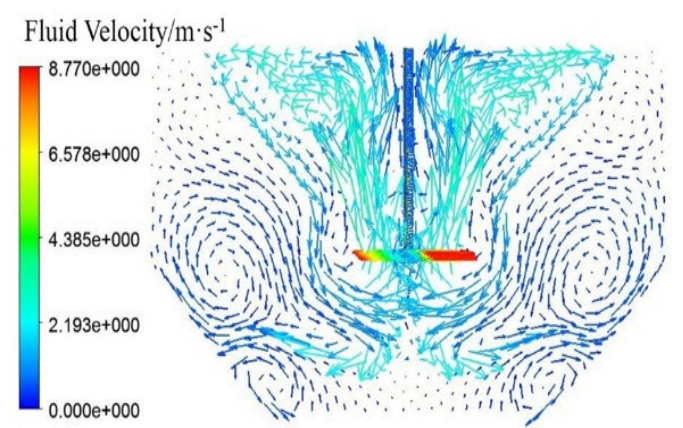

b) Central cross-section velocity 
Fig. 4. Velocity vector of the fluid under the condition of feed particle content of $32 \%$, the particle size of $15 \mathrm{~mm}$ and stirring speed of $60 \mathrm{rpm}$

\section{Particle velocity field distribution and solid volume fraction distribution}

The velocity vector of the particle can represent the velocity field distribution of the particle, as shown in Fig. 5 (a). Compared with Fig. 4, it shows that the relative distributions of the fluid flow field and the particle flow field are almost the same apart from that there is nearly no velocity distribution in the crystallization zone. This is because of the speed function of the particle, and the fluid is similar after considering the effect of all the forces of the particles. Under this circumstance, the particle velocity field can form a circulation inside the crystallizer.

In this paper, the solid volume fraction distribution represents the distribution of the particle concentration at various locations in the crystallizer while the work is steady. This state is particularly important to assess the performance of the crystallisation process. As Fig. 5 (b) shown, the particles are mainly distributed in the circulation zone under the action of the fluid through the agitation. The distribution of the particles is relatively uniform, and the distribution in the crystallisation zone is very small. In the circulation zone along the loop path, the particles volume fraction reaches at least roughly $10 \%$. The crystallizer has enough power to push the particle phase and the fluid phase to form a circulation in the crystallizer. In the meanwhile, a small amount staying at the bowl baffle. In the crystallisation zone, particle concentration tends to be zero because most of the content is fluid.

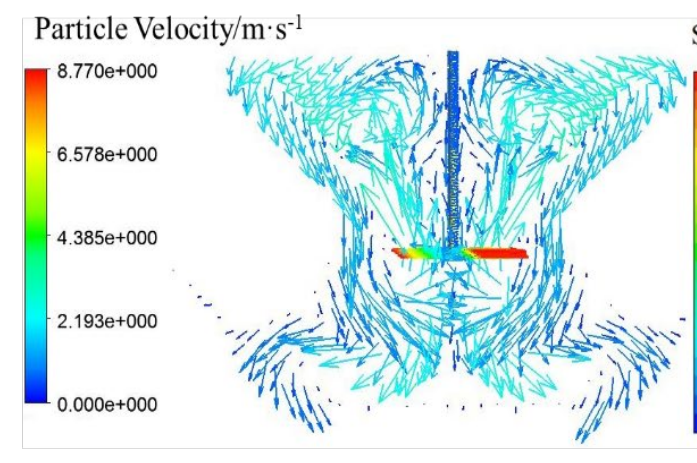

a) particle velocity distribution

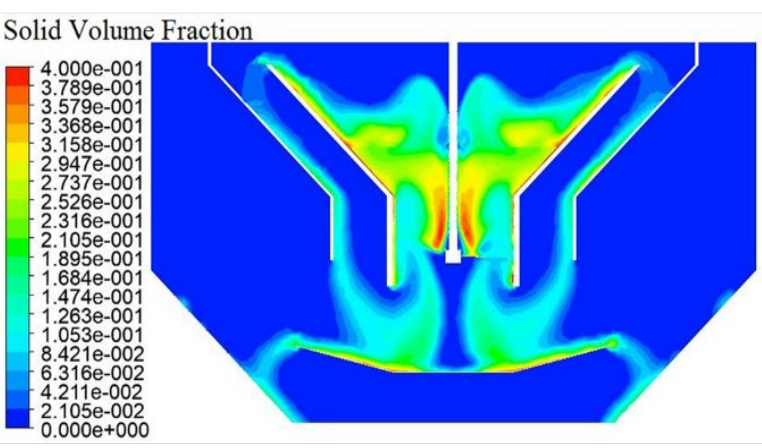

b) solid volume fraction distribution 
Fig. 5. Distribution of particle velocity and solid volume fraction distribution under the condition of feed particle content of $32 \%$, the particle size of $15 \mathrm{~mm}$ and stirring speed of 60 rpm

\section{Pressure field distribution}

In the crystallizer, the pressure field is part of the flow field, studying the pressure field can more clearly understand the effect of pressure difference on speed, and researching the pressure field has great significance for studying the structure of the mixing paddle. The pressure distribution at a point is related to the particle concentration at that point and the velocity of the two phases. As Fig. 6 shows, the pressure distribution in the crystallizer changes significantly in the circulation zone with a fluctuation range between 52,350 Pa and $105,500 \mathrm{~Pa}$. This is because the particles are non-uniformly distributed at various locations, and each of the locations has different velocity as well. The pressure fluctuates around 100,000 $\mathrm{Pa}$ on bowl-type baffles and the upper part of the outer cylinder. This is because there are more particles in this area, and hence, a higher pressure. The least pressure occurs at the bottom of the main stirring device, which is $52,350 \mathrm{~Pa}$.

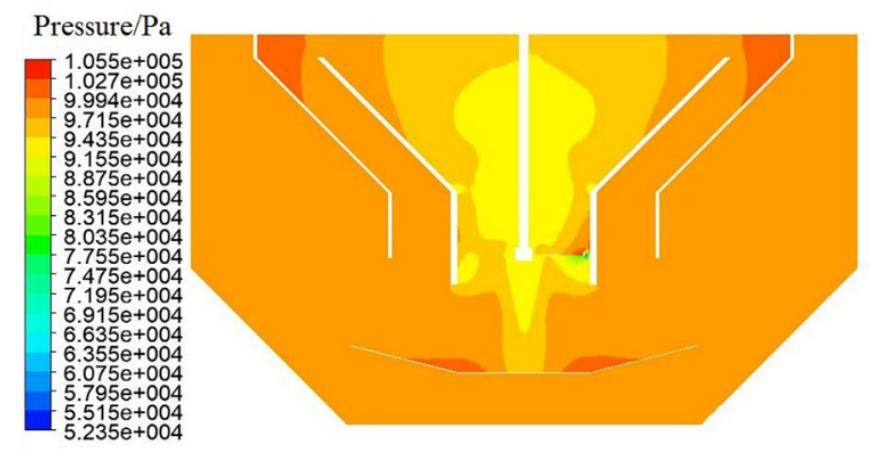

Fig. 6. The pressure contours under the condition of feed particle content of $32 \%$, the particle size of $15 \mathrm{~mm}$ and stirring speed of $60 \mathrm{rpm}$

\section{Flow field model validation}

The flow field solution method was used to simulate the flow field in the DTB industrial crystallizer under certain operating conditions in the article (Wu et al. 2009). The velocity 
vector of the fluid is shown in Fig. 7. The flow field simulation results are basically consistent with the literature results, and the error of velocity field distribution is $3.2 \%$. It is proved that the CFD simulation method in this paper is reasonable and effective, and the results are credible.

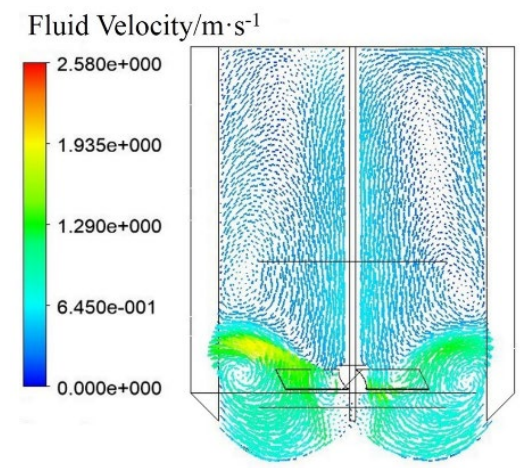

Fig. 7. Velocity vector of the fluid in the DTB industrial crystallizer under the condition of stirring speed of $600 \mathrm{rpm}$

\section{Influencing Factors on coupling flow field in two-phase in the crystallizer}

The performance of the crystallisation depends largely on the flow field distribution of fluid and particles in the crystallizer. Therefore, fully suspended particles and the uniformly circulated flow field are key essentials to ensure a great crystallisation. This paper analyses the coupled flow field of the two-phase flow in a crystallizer, in terms of the stirring speed, particle size and feeding particle concentration. Based on the simulation of the particle-fluid two-phase coupled flow field, the main variation of flow field appears at the circulation zone in the crystalliser, and the flow field distribution in this area has the most impact on the crystallisation process. Therefore, the analysis of flow field focuses on this circulation zone. In order to facilitate the quantitative analysis and ease the comparison of flow field simulation results, eight typical points from the material recycling zone, in the axial central cross-section, are selected as shown in Fig. 8, and typical location coordinates of the eight points are shown in Table 2. 


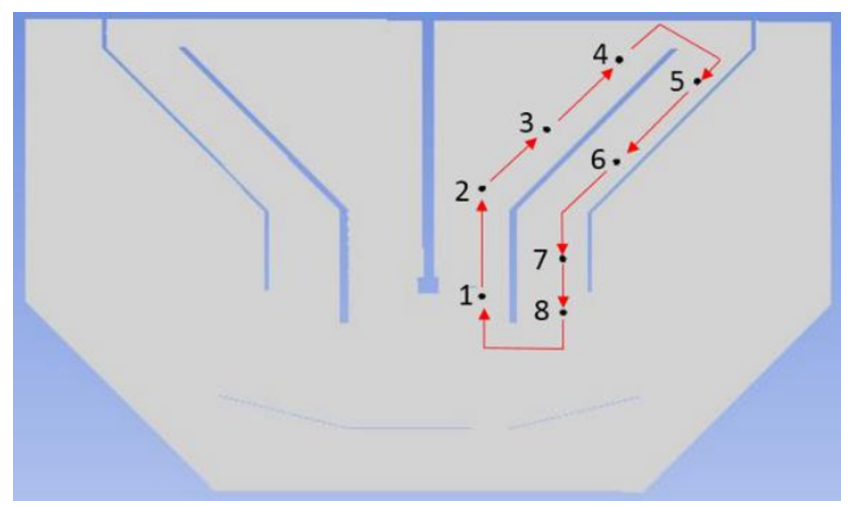

Fig. 8. Axial central cross-section

Table 2. Typical location coordinates

\begin{tabular}{cccc}
\hline & $\mathrm{x} / \mathrm{m}$ & $\mathrm{y} / \mathrm{m}$ & $\mathrm{z} / \mathrm{m}$ \\
\hline Point 1 & 1 & 0.5 & 0 \\
Point 2 & 1 & 2.5 & 0 \\
Point 3 & 2.2 & 3.6 & 0 \\
Point 4 & 3.55 & 4.9 & 0 \\
Point 5 & 5 & 4.5 & 0 \\
Point 6 & 3.5 & 3 & 0 \\
Point 7 & 2.5 & 1.2 & 0 \\
Point 8 & 2.5 & 0.2 & 0 \\
\hline
\end{tabular}

\section{Effect of Stirring Speed on Crystallizer Coupling Flow Field}

The simulation configurations are listed in Table 3.

Table 3. The configuration of stirring speed simulation

\begin{tabular}{cc}
\hline Working condition & Values \\
\hline Inlet velocity $(\mathrm{m} / \mathrm{s})$ & 0.167 \\
Outlet pressure $/ \mathrm{Pa}$ & 99671 \\
Particle diameter $/ \mathrm{mm}$ & 12 \\
Feed particle content $(\%)$ & 32 \\
Stirring speed $(\mathrm{rpm})$ & $40 、 50 、 60$ \\
\hline
\end{tabular}

Fig. 9 indicates that the stirring speed has a significant impact on the distribution of the fluid velocity field. In general, the velocity of fluid measured at each point are increasing with an increase in the stirring speed and the distribution of velocity field becomes more 
evenly. The lower velocity at point 2 , compared to point 3 , is caused by the eddy current formed in the zone above the main mixing device. The maximum velocity difference of the points measured on circulation path is $0.93 \mathrm{~m} / \mathrm{s}$ at the stirring speed between $40 \mathrm{rpm}$ and 50 $\mathrm{rpm}$, while the value is $0.62 \mathrm{~m} / \mathrm{s}$ at the stirring speed between $50 \mathrm{rpm}$ and $60 \mathrm{rpm}$.

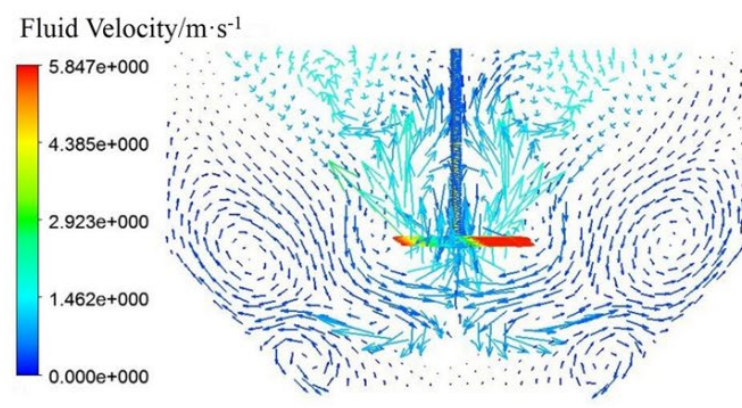

Fluid Velocity $/ \mathrm{m} \cdot \mathrm{s}^{-1} \quad$ a) $\mathrm{n}=40 \mathrm{rpm}$

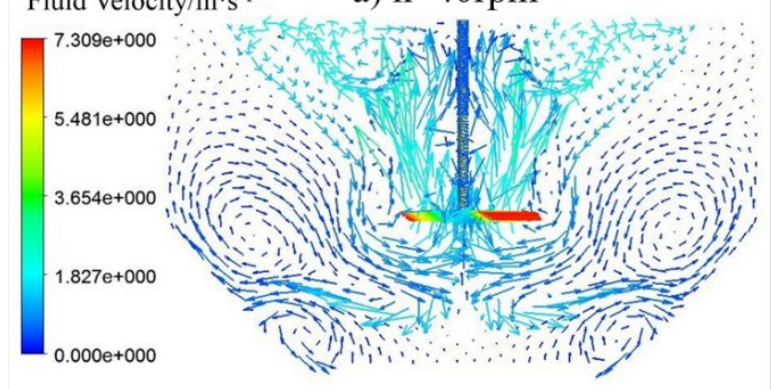

c) $n=60 \mathrm{rpm}$

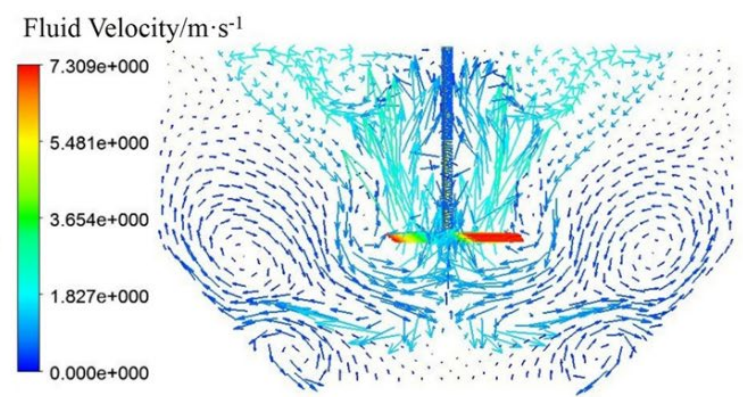

b) $\mathrm{n}=50 \mathrm{rpm}$

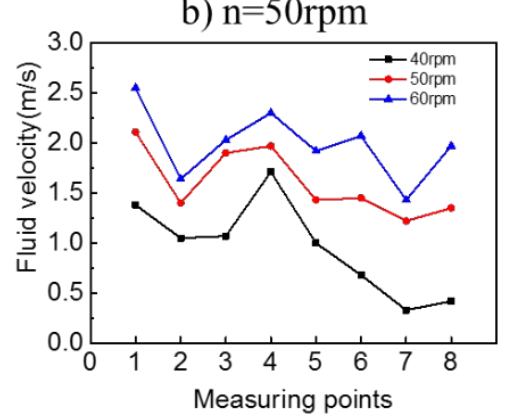

d) fluid velocity distribution of typical locations

Fig. 9. The fluid velocity vectors and the velocity distribution at each typical position with different rotational speeds

Fig. 10 shows that the solid volume fraction distribution is more evenly with an increase in the stirring speed. At the stirring speed of $40 \mathrm{rpm}$, the solid volume fraction at point 3 to 8 is close to zero. This indicates that the main mixer has insufficient power to ensure cyclic crystallization. At stirring speed of $50 \mathrm{rpm}$, all points have solid volume fraction above roughly $10 \%$ and solid volume fraction distribution in the crystallizer is more uniform. Although the higher stirring speed leads to a better solid volume fraction distribution, the most effective stirring speed is still recommended to be around $50 \mathrm{rpm}$. This is because higher stirring speed also leads to an increase in the particle collision force during the crystallisation process. Hence, the larger particles experience a higher risk of cash into pieces, and thus, this provides a negative effect of the crystallisation process. Last but not least, higher stirring speed requires a larger motor and increasing the rate of secondary nucleation of the crystal. 
Solid Volume Fraction

$4.000 \mathrm{e}-001$
$3.714 \mathrm{e}-001$
$3.429 \mathrm{e}-001$

$3.429 \mathrm{e}-001$

- $3.143 \mathrm{e}-001$

$2.857 \mathrm{e}-001$
$2.571 \mathrm{e}-001$

$2.286 \mathrm{e}-00$

$2.000 \mathrm{e}-001$

$1.714 \mathrm{e}-00$

$.429 \mathrm{e}-001$

$1.143 \mathrm{e}-001$

$8.571 \mathrm{e}-002$

$2.857 \mathrm{e}-002$

$0.000 \mathrm{e}+000$

Solid Volume Fraction

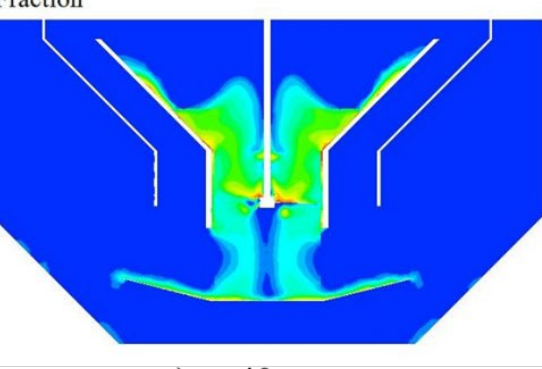

a) $n=4$ rnm

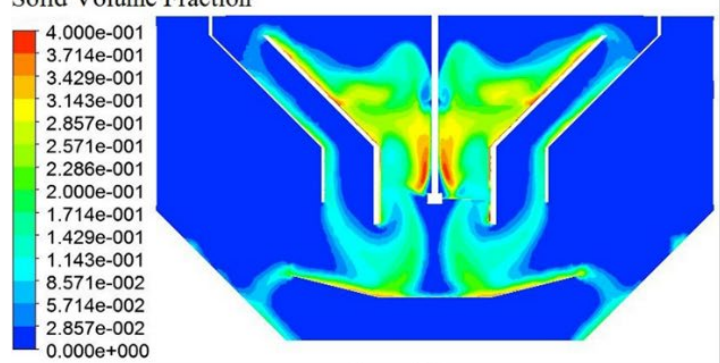

c) n=60rpm
Solid Volume Fraction

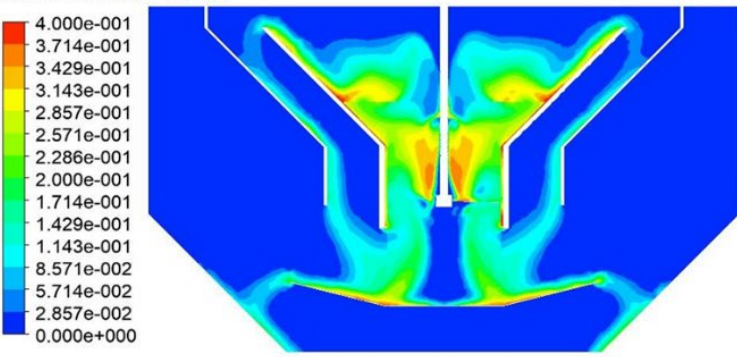

b) $\mathrm{n}=50 \mathrm{rpm}$

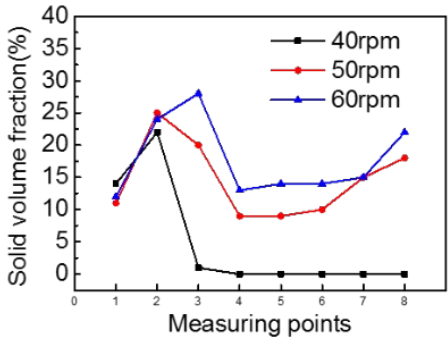

d) solid volume fraction distribution of typical locations

Fig. 10. The solid volume fractions and the velocity distribution at each typical position with different rotational speeds

Fig. 11 indicates that the pressure decreases with an increase of stirring speed, and the pressure distribution is more evenly with a decrease in the stirring speed. At stirring speed of $40 \mathrm{rpm}$, the pressure distribution in the circulation zone is the most uniform distribution, and the maximum pressure difference value of those 8 points is $5326 \mathrm{~Pa}$, while the values are respectively $6820 \mathrm{~Pa}$ and $9210 \mathrm{~Pa}$ at stirring speed of $50 \mathrm{rpm}$ and $60 \mathrm{rpm}$.

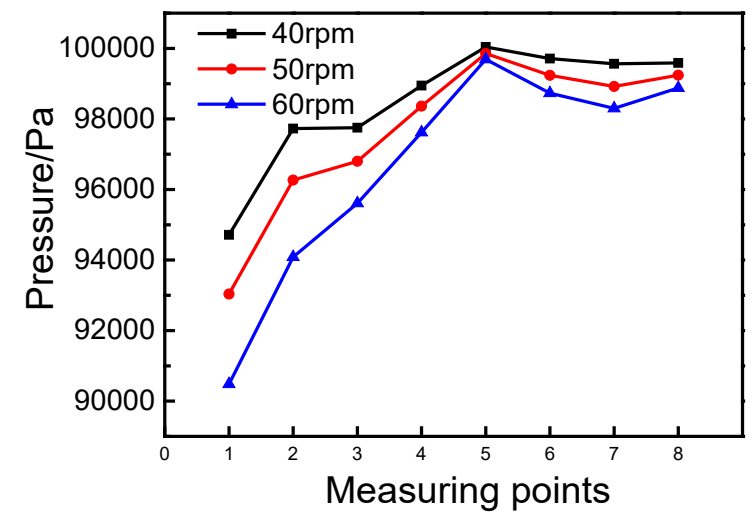

Fig. 11. Pressure values of each typical locations at various rotational speeds

\section{Effect of particle size on Crystallizer Coupling Flow Field}

The simulation configurations are listed in Table 4. 
Table 4. The configuration of particle size simulation

\begin{tabular}{cc}
\hline Working condition & Values \\
\hline Inlet velocity $(\mathrm{m} / \mathrm{s})$ & 0.167 \\
Outlet pressure $/ \mathrm{Pa}$ & 99671 \\
Stirring speed $(\mathrm{rpm})$ & 50 \\
Feed particle content $(\%)$ & 32 \\
Particle diameter $/ \mathrm{mm}$ & 4、12、20 \\
\hline
\end{tabular}

Fig. 12 indicates that the distributions of fluid velocity are roughly the same concerning the change of the particle sizes, and the variation between the measured velocities is extremely small. The maximum difference point is at point 3 , which is about $0.28 \mathrm{~m} / \mathrm{s}$. The particle size has less impact on the velocity field of the fluid.

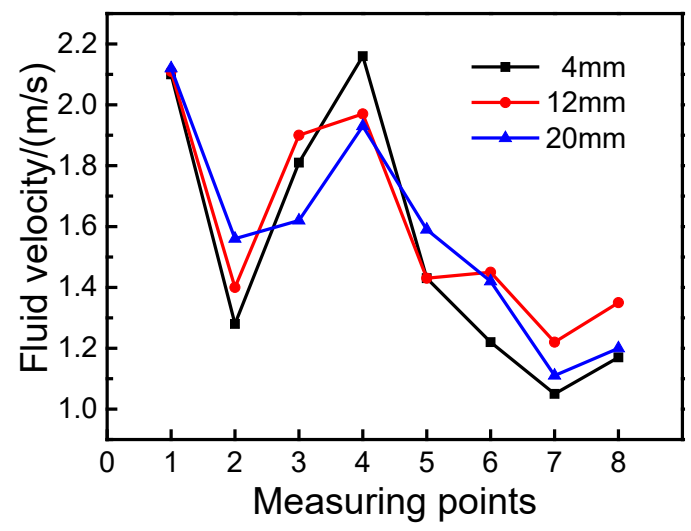

Fig. 12. The velocity distribution at each typical location with different particle sizes

Fig. 13 indicates that the particle sizes have a great impact on the solid volume fraction distribution. Particles with smaller sizes tend to lead to a more uniform solid volume fraction distribution. The larger particle size leads to a larger fluctuation in the particle volume fraction. At particle size of $12 \mathrm{~mm}$, the solid volume fraction of all points reaches roughly $10 \%$ at least. With $20 \mathrm{~mm}$ in particle diameter, the solid volume fraction is approximately zero. This means that the solid particles in the draft tube are not able to flow into the annular circulation zone, and thus, the circulation effect is not well performed. As a result, the maximum particle size is around $12 \mathrm{~mm}$ in order to ensure the cyclic crystallisation. 


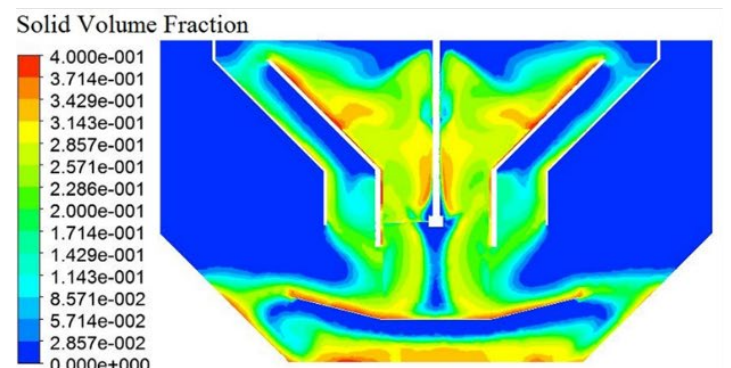

a) $\mathrm{d}=4 \mathrm{~mm}$

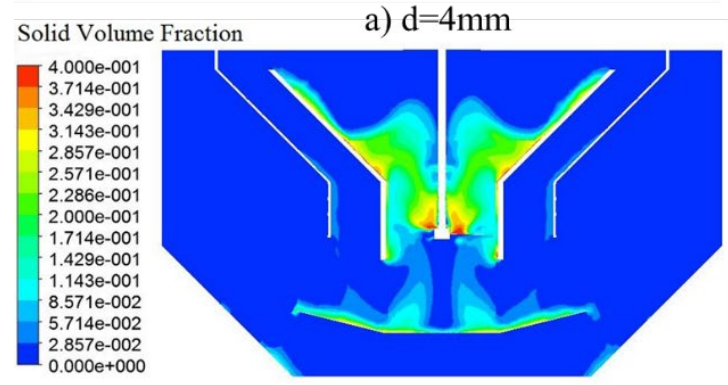

c) $\mathrm{d}=20 \mathrm{~mm}$

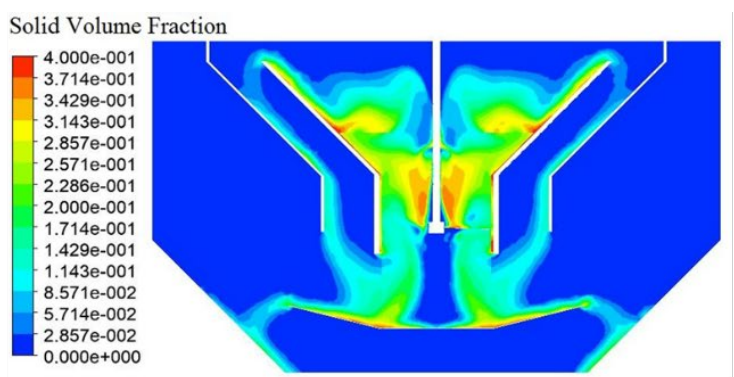

b) $\mathrm{d}=12 \mathrm{~mm}$

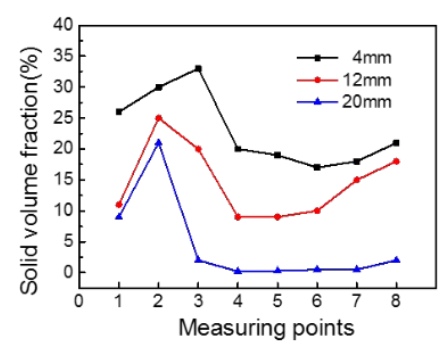

d) solid volume fraction distributions of typical locations

Fig. 13. The solid volume fraction distribution and the solid volume fraction at each typical position with different particle sizes

As Fig. 14 shows, the pressure distribution is also affected by the particle size. The pressure at the point measured on the circulation path increases as the particle size increases, At particle size of $12 \mathrm{~mm}$, the pressure distribution in the circulation zone is the most uniform distribution, and the maximum pressure difference value of those 8 points is $6820 \mathrm{~Pa}$, while the values are respectively $7841 \mathrm{~Pa}$ and $7483 \mathrm{~Pa}$ at particle size of $4 \mathrm{~mm}$ and $20 \mathrm{~mm}$.

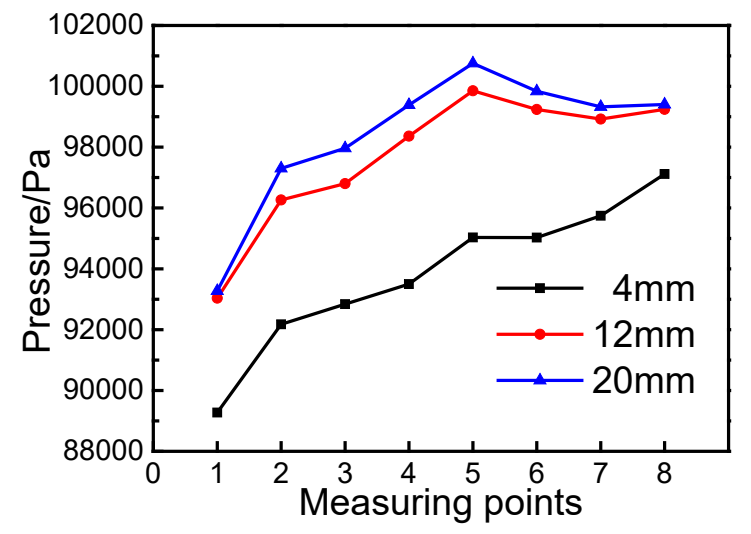

Fig. 14. The pressure distribution at each typical location with different particle sizes 


\section{Effect of feed particle concentration on Crystallizer Coupling Flow Field}

The simulation configurations are listed in Table 5.

Table 5. The configuration of particle concentration simulation

\begin{tabular}{cc}
\hline Working condition & Values \\
\hline Inlet velocity $(\mathrm{m} / \mathrm{s})$ & 0.167 \\
Outlet pressure $/ \mathrm{Pa}$ & 99671 \\
Particle diameter $/ \mathrm{mm}$ & 12 \\
Stirring speed $(\mathrm{rpm})$ & 50
\end{tabular}

Feed particle concentration $\quad(\%) \quad 21,32 、 43$

Fig. 15 shows that the flow field distribution in the crystallizer is roughly the same. Fluid velocity is able to boost the circulation in the circulation zone. Among the eight points of the study, the largest difference of the speed is at point 3 , which is $0.96 \mathrm{~m} / \mathrm{s}$. The feed particle concentration has less effect on the velocity field of the fluid. The best uniform velocity distribution occurs at the concentration of $32 \%$.

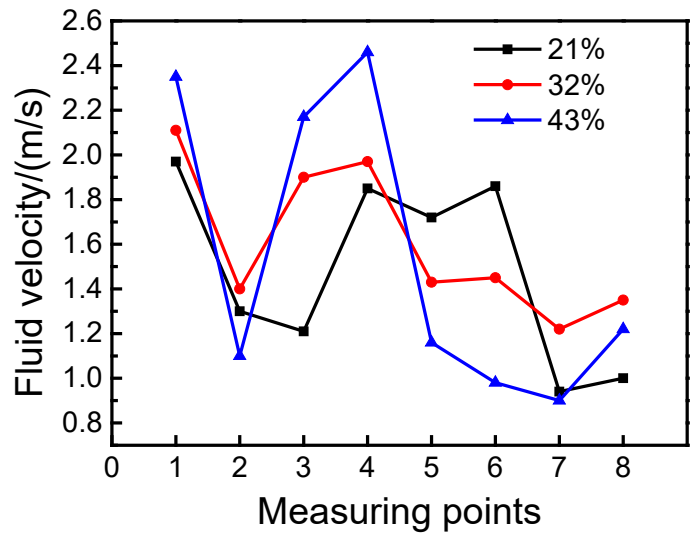

Fig. 15. The velocity distribution at each typical location with different feed particle concentration

Fig. 16 shows that the distribution of solids in the crystallizer is strongly related to the particle feed concentration. When the feed concentration of solid particles is low $(21 \%)$, the volume fraction of solid particles on the circulation path is lower. This is because the particle concentration is too small, and therefore, it cannot create good circulation in the crystallizer. When the concentration of solid particles is $32 \%$ or $43 \%$, the solid volume fraction of those 
eight points all reach roughly $10 \%$ at least. As a result, this indicates the formation of good circulation.

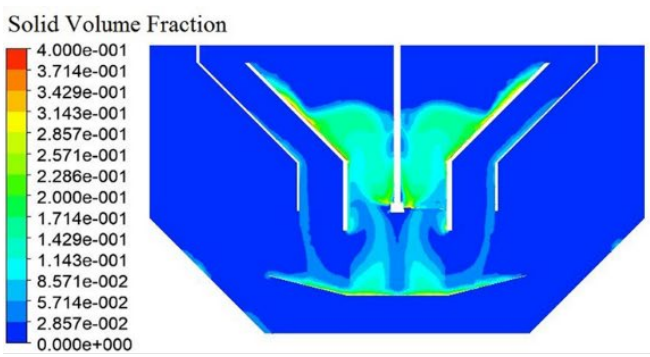

a) $\mathrm{p}=21 \%$

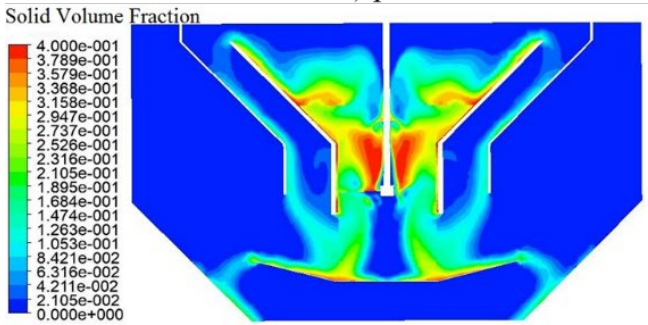

c) $\mathrm{p}=43 \%$

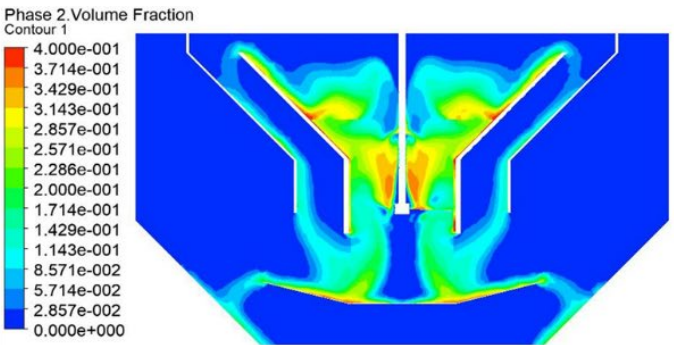

b) $\mathrm{p}=32 \%$

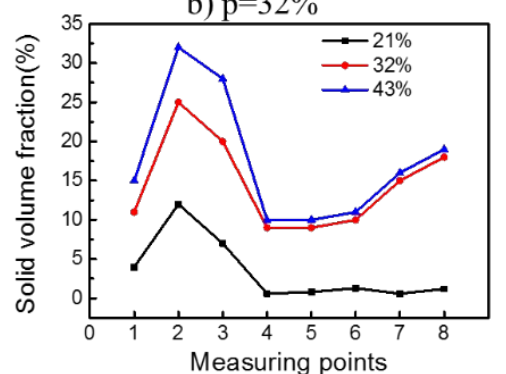

d) solid volume distribution of typical locations

Fig. 16. The solid volume fraction distribution and the solid volume fraction at each typical position with different feed particle concentration

Fig. 17 shows the pressure is also affected by the feed particle concentration. In general, the lower the particle concentration is, the greater the pressure is, When the particle concentration is $21 \%$, the pressure distribution has a larger fluctuation, the maximum pressure difference value of those 8 points is $7639 \mathrm{~Pa}$ in this condition, while the pressure values are respectively $6820 \mathrm{~Pa}$ and $6074 \mathrm{~Pa}$ at particle concentration of $32 \%$ and $43 \%$, so the pressure distribution tends to be steadier when the particle concentration is $32 \%$ or $43 \%$.

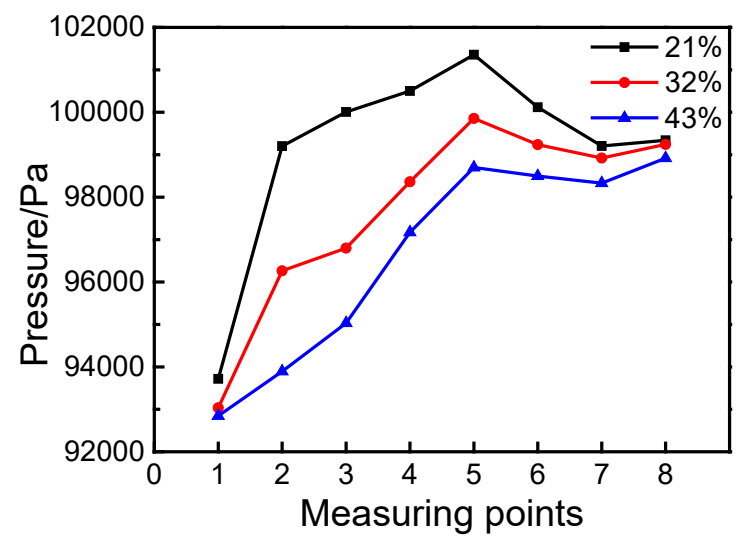

Fig. 17. The pressure distribution at each typical location with different feed particle concentration 


\section{Conclusions}

In this paper, the two-fluid model considers the fluid and particle phases as a continuous media throughout the entire flow field, and the particle phase was defined as pseudo-fluid. The coupling effect between the fluid and the particles is also taken into consideration. The momentum balance equation is determined from the Navier-Stokes equation by including the phase momentum transfer term. The modified equation, for the determination of the particle-fluid two-phase flow field, also considers the interaction effect of particle-to-particle and particle-to-fluid. Last but not least, the effect of virtual mass force on particle acceleration is also considered. The research method provides a reference for the study of coupled flow field and its influencing factors regarding the flow of two-phase.

The flow field of the two-phase flow during the crystallisation process of potassium salt in a crystallizer is studied. The influencing factors, which is stirring speed, particle size and feed particle concentration, are simulated and analysed. The stirring speed has the most obvious impact on the coupling flow field, and the minimum stirring speed is controlled at roughly $50 \mathrm{rpm}$ to ensure cyclic crystallization, while the maximum pressure difference value of typical 8 points is $6820 \mathrm{~Pa}$ in this condition. In addition, the particle size and feed particle concentration have a smaller impact on the velocity distribution of the two-phase flow. In the same condition of stirring speed, which is $50 \mathrm{rpm}$, the maximum particle size is controlled at roughly $12 \mathrm{~mm}$ to ensure cyclic crystallization, the maximum pressure difference value of typical 8 points at the particle size of $12 \mathrm{~mm}$ is $6820 \mathrm{~Pa}$. The flow field is stable and circular only at the feed particle concentration of roughly $32 \%$, and the maximum pressure difference value of typical 8 points is $6820 \mathrm{~Pa}$ in this condition.

These simulation results provide the basis for the feasibility of the coupling algorithm and provide theoretical guidance for the optimisation of operating conditions in the production and application of potassium salt crystallizer.

Acknowledgements. We are grateful for the financial support provided by the Fundamental Research Funds for the Central Universities (FRF-GF-17-B21). 


\section{Symbols}

$C_{1}, C_{2}, C_{\mu} \quad$ turbulence model constants

$\overrightarrow{F_{l s}} \quad$ interphase forces between the particle phase and the

$\begin{array}{llc}\text { fluid phase } & & \mathrm{N} \\ f_{m} & \text { virtual mass force } & \mathrm{N} \\ \vec{g} & \text { gravity acceleration } & \mathrm{m} / \mathrm{s}^{2} \\ g_{0} & \text { radial distribution function } & \\ k & \text { turbulent kinetic energy } & \mathrm{m}^{2} \mathrm{~s}^{-2} \\ \overrightarrow{u_{j}} & \text { velocity vector of j phase } & \mathrm{m} / \mathrm{s} \\ R e & \text { Reynolds number } & \\ p & \text { static pressure } & \mathrm{Pa} \\ p_{s} & \text { particle pressure } & \mathrm{Pa} \\ T & \text { temperature } & \mathrm{K} \\ t & \text { time } & \mathrm{h}\end{array}$

\section{Greek Letters}

$\varepsilon$

volume fraction of phase $j$

$\rho_{j}$

density of $j$ phase

$\mathrm{kg} \mathrm{m}^{-3}$

$\overrightarrow{\tau_{l}}$

viscous stress tensor of liquid phase

$\mathrm{N} \mathrm{m}^{-2}$

$\mu_{t}$

eddy viscosity for the liquid phase

$\mathrm{kg} \mathrm{m}^{-1} \mathrm{~s}^{-1}$

$\mu_{f}$

effective viscosity of the fluid

$\mathrm{kg} \mathrm{m} \mathrm{m}^{-1} \mathrm{~s}^{-1}$

$\alpha$

heat transfer coefficient

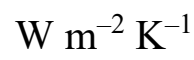

$\varepsilon$

dissipation rate of turbulent kinetic energy

$\mathrm{m}^{2} \mathrm{~s}^{-3}$

$\sigma_{k}, \sigma_{\varepsilon}$

turbulence model constants

$\overrightarrow{\tau_{s}}$

particle stress tensor

$\mathrm{N} \mathrm{m}^{-2}$

$\xi_{s}$

granular bulk viscosity

$\mathrm{kg} \mathrm{m}^{-1} \mathrm{~s}^{-1}$ 
$\mu_{s} \quad$ solids viscosity $\quad \mathrm{kg} \mathrm{m}^{-1} \mathrm{~s}^{-1}$

$\begin{array}{ll}\text { Subscripts } & \\ j & \text { number of phases } \\ l & \text { liquid phase } \\ s & \text { solid phase }\end{array}$

\section{References}

Chen SH, Liao C, Sciortino F, Gallo P, Tartaglia P (1999) Model for single-particle dynamics in supercooled water. Physical Review E, 59(6), 6708. doi: 10.1103/PhysRevE.59.6708

Chen X, Wang J (2014) A comparison of two-fluid model, dense discrete particle model and CFD-DEM method for modelling impinging gas-solid flows. Powder Technology. 254, 94-102. doi: 10.1016/j.powtec.2013.12.056

Schwarzkopf JD, Sommerfeld M, Crowe CT, Tsuji Y (2011) Multiphase flow with droplets and particles. CRC press. doi: org/10.1201/b11103

Ding J, Gidaspow D (1990) A bubbling fluidization model using kinetic theory of granular flow. AIChE Journal, 36(4), 523-538. doi: 10.1002/aic.690360404

Elger DF, Roberson JA (2016) Engineering fluid mechanics. Hoboken (NJ): Wiley, pp $170-185$

Ergun S (1952) Fluid flow through packed columns. Chemical Engineering Progress, 48, 89-94.

Gidaspow D (1993) Hydrodynamic modelling of circulating and bubbling fluidized beds. Particulate Two-Phase Flow (ed. MC Roco), 778-810.

Gus'kov OB (2012) The virtual mass of a sphere in a suspension of spherical particle s. Journal of Applied Mathematics and Mechanics, 76(1), 93-97. doi: 10.1016/j.jappm-a thmech.2012.03.007 
Hosseini S, Patel D, Ein-Mozaffari F, Mehrvar M (2010) Study of solid-liquid mixing in agitated tanks through computational fluid dynamics modelling. Industrial \& Engineering Chemistry Research, 49(9), 4426-4435. doi: 10.1021/ie901130z

Huilin L, Yurong H, Wentie L, Ding J, Gidaspow D, Bouillard J (2004) Computer simulations of gas-solid flow in spouted beds using kinetic-frictional stress model of granular flow. Chemical Engineering Science, 59(4), 865-878. doi: 10.1016/j.ces.2003.10.018

Jiang P, Wang XK, Fang BL, Sha ZL (2013) Distribution Features of Multi-Phase Flow in DTB Crystallizer. In Applied Mechanics and Materials. Trans Tech Publications, 295, 3055-3061. doi: 10.4028/www.scientific.net/AMM.295-298.3055

Kendoush AA, Sulaymon AH, Mohammed SA (2007) Experimental evaluation of the virtual mass of two solid spheres accelerating in fluids. Experimental Thermal and Fluid Science, 31(7), 813-823. doi: 10.1016/j.expthermflusci.2006.08.007

Ljungqvist M, Rasmuson A (2001) Numerical simulation of the two-phase flow in an axially stirred vessel. Chemical Engineering Research and Design, 79(5), 533-546. doi: $10.1205 / 02638760152424307$

Pratt DT, Smoot L, Pratt D (1979) Pulverized coal combustion and gasification. Springer.

Raeini AQ, Blunt MJ, Bijeljic B (2012) Modelling two-phase flow in porous media at the pore scale using the volume-of-fluid method. Journal of Computational Physics, 231(17), 5653-5668. doi: 10.1016/j.jcp.2012.04.011

Roco MC (Ed.) (1993) Particulate two-phase flow. Boston, MA: Butterworth-Heinemann.

Sha Z, Palosaari S (2002) Modeling and simulation of crystal size distribution in imperfectly mixed suspension crystallization. Journal of Chemical Engineering of Japan, 35(11), 1188-1195. doi: 10.1252/jcej.35.1188 
Sha Z, Xiong C, Chen Q (2013) Scale-up of a Fluidized Bed Crystallizer on the Basi s of Solid Suspension. Chemical Engineering \& Technology, 36(8), 1307-1312. doi: 10. 1002/ceat.201300018

Wadnerkar D, Utikar RP, Tade MO, Pareek VK (2012) CFD simulation of solid-liquid stirred tanks. Advanced Powder Technology, 23(4), 445-453. doi: 10.1016/j.apt.2012.03.007

Wei W, Youchu L (2000) Progress of the simulation of particle-fluid two-phase flow. Progress in Chemistry Beijing, 12(2), 208-217. doi: 10.3321/j.issn:1005-281X.2000.02.0 10

Wen CY (1966) Mechanics of fluidization. In Chem. Eng. Prog. Symp. Ser. 62, 100-111.

Wu S, Wang X, Sha Z, Wang Y (2009) Solution of population balance in multiphase flow field for industrial crystallization process. Journal of the Chemical Industry and Engineering Society of China, 60(3), 593-600. doi: 10.3321/j.issn:0438-1157.2009.03.009

Zhiqing Y (1994). 2. Application Collocation. In Advances in chemical engineering. Academic Press, 20, 39-83. doi: 10.1016/S0065-2377(08)60297-5

Zhu HP, Zhou ZY, Yang RY, Yu AB (2007) Discrete particle simulation of particulate systems: theoretical developments. Chemical Engineering Science, 62(13), 3378-3396. doi: 10.1016/j.ces.2006.12.089 